\title{
Laminar Sheet Flow of Paste Material
}

\author{
R. Haldenwang Cape Peninsula University of Technology, South Africa \\ P.T. Slatter Cape Peninsula University of Technology, South Africa \\ R.P. Chhabra Indian Institute of Technology, India
}

\begin{abstract}
There is considerable pressure to operate tailings slurry disposal sites at higher solids concentrations. This has the effect of both increasing the viscosity and causing the viscous character of the resulting slurry to become increasingly non-Newtonian and paste like in nature. Ultimately viscous forces dominate and the flow becomes laminar. After exit from the spigot, the material will flow as an unconfined sheet at the disposal site. The properties of this sheet flow will profoundly affect the operation of the disposal facility. This paper introduces a new approach to the analysis of the laminar sheet flow of a general time independent non-Newtonian material. In particular, a new scaling parameter is introduced which relates the sheet flow directly to its rheological properties. The validity of the new approach is confirmed by comparison with experimental results.
\end{abstract}

\section{Introduction}

Tailings disposal is very complex in nature because the mineralogy of tailings changes continuously. This affects the rheology or flow behaviour. With increase in concentration the materials become more viscous and non-Newtonian in nature and the flow behaviour more difficult to predict. Stacking these tailings at required slopes is not easy and not many accurate predictive models are available.

Ultimately, viscous forces dominate and the flow becomes laminar. After exit from the spigot, the material will flow as an unconfined sheet at the disposal site. The properties of this sheet flow will profoundly affect the operation of the disposal facility. Often tests are conducted in flumes to understand and predict the freesurface sheet flow behaviour of the thickened tailings material. The objective of this paper is to introduce a new approach to the analysis of the laminar sheet flow of a general time independent non-Newtonian material. In particular, a new scaling parameter is developed from fundamental principles, which relates the sheet flow directly to its rheological properties. The validity of the new approach is confirmed by comparison with experimental results.

\section{Literature and theory}

Haldenwang et al. (2004a) presented a sheet film approach using the equation published by De Kee et al. (1990). Several concentrations of three rheologically different non-Newtonian fluids were tested in a $10 \mathrm{~m}$ tilting flume.

The results showed that for the power law fluid (CMC) the velocity predictions were reasonable. However, for the two yield stress fluids bentonite and kaolin in water suspensions, the predictions were not good. This indicated that the yield stress seems to have an effect in laminar flow making the predictions difficult. 
The shear stress $\tau$ for sheet flow increases linearly with depth $h$, from zero at the free surface to the wall shear stress $\tau_{0}$ at depth $H$ as indicated in Figure 1. The shear stress distribution is:

$$
\tau=\rho g h \sin \alpha,
$$

Where:

$$
\begin{array}{lll}
\rho & = & \text { the fluid density }\left(\mathrm{kg} / \mathrm{m}^{3}\right) \\
h & = & \text { the height of fluid in the sheet }(\mathrm{m}) \\
\alpha & = & \text { horizontal (degrees) } \\
g & = & \text { gravitational acceleration }\left(\mathrm{m} / \mathrm{s}^{2}\right)
\end{array}
$$

The shear stress distribution is shown in Figure 1 (Chow, 1959).

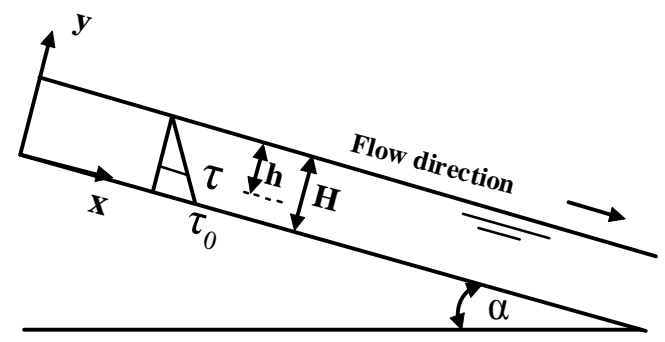

\section{Figure 1 Shear stress distribution for sheet flow}

The equation for laminar Newtonian sheet flow is obtained by integrating Equation (1) over the flow depth (Chow, 1959):

$$
Q=\frac{H^{2} \tau_{0}}{3 \mu}
$$

Where:

$$
\begin{array}{rll}
Q & = & \text { volumetric flow rate }\left(\mathrm{m}^{3} / \mathrm{s} / \mathrm{m}\right) \\
H & = & \text { fluid height }(\mathrm{m}) \\
\tau_{0} & = & \text { wall shear stress }(\mathrm{Pa}) \\
\mu & = & \text { dynamic viscosity (Pa.s) }
\end{array}
$$

In terms of the mean velocity $V$

$$
V=\frac{Q}{H}=\frac{H \tau_{0}}{3 \mu}
$$

Where:

$$
V \quad=\quad \text { mean velocity }(\mathrm{m} / \mathrm{s})
$$

For a Newtonian fluid the shear rheology relationship is:

$$
\dot{\gamma}=\frac{\tau}{\mu} \quad \text { and } \quad \dot{\gamma}_{0}=\frac{\tau_{0}}{\mu}
$$

Where $\dot{\gamma}=$ the shear rate $\left(\mathrm{s}^{-1}\right)$ and $\dot{\gamma}_{0}=$ the wall shear rate $\left(\mathrm{s}^{-1}\right)$. 
If Equations 3 and 4 are combined and if this is expressed in terms of the wall shear stress and the wall shear rate the relationship is as follows:

$$
\tau_{0}=\mu \frac{3 V}{H}=\mu \dot{\gamma}_{0}
$$

Therefore:

$$
\dot{\gamma}_{0}=\frac{3 V}{H}
$$

which gives us the bulk sheetflow shear rate.

The wall shear stress for sheet flow is:

$$
\tau_{0}=\rho g H \sin \alpha
$$

With this a unique relationship between the shear rate and shear stress is presented which is independent of the rheology of the fluid. Laminar sheet flow can therefore be represented and analysed as a unique relationship between wall shear stress $\tau_{0}$ and bulk shear rate $3 \mathrm{~V} / \mathrm{H}$, as is customarily done for pipe flow.

Dimensionless groups used previously by the authors for free surface flow analyses are (Haldenwang et al., 2004a):

The Fanning friction factor $f$

$$
f=\frac{2 R_{h} g \sin \theta}{V^{2}},
$$

Where $R_{h}$ is the hydraulic radius; the yield pseudoplastic Reynolds number $\left(\operatorname{Re}_{2(\mathrm{YPP})}\right)$

$$
\operatorname{Re}_{2(Y P P)}=\frac{8 \rho V^{2}}{\tau_{y}+K\left(\frac{2 V}{R_{h}}\right)^{n}},
$$

and the Froude number $(F r)$

$$
F r=\frac{V}{\sqrt{g H}}
$$

\section{Experimental procedure}

The experimental work was conducted by the Flow Process Research Centre at the Cape Peninsula University of Technology in a $10 \mathrm{~m}$ long tilting flume which is $300 \mathrm{~mm}$ wide with slopes from 1 to $5^{\circ}$.

The flow rates achieved by the progressive cavity positive displacement pump is $24 \mathrm{l} / \mathrm{s}$ but higher flow rates up to $45 \mathrm{l} / \mathrm{s}$ were achieved using a centrifugal pump. The flow heights in the channel were measured using digital depth gauges which were linked to the computer but had to be lowered manually to the surface of the fluid in the flume.

The rheology of the fluids were measured in a tube viscometer with three tubes $(13,28$ and $80 \mathrm{~mm}$ diameter respectively) which is in-line with the tilting flume. Magnetic flow meters and differential pressure transducers are fitted to each line for measuring flow rates and pressure drops. A mass flow meter is fitted to the $13 \mathrm{~mm}$ line which can also provide density and temperature readings. More detail is provided with regard to the experimental procedures and accuracies obtained are presented in Haldenwang (2003) and Haldenwang and Slatter (2006). 


\section{Results}

In Figure 2 a plot of wall shear stress versus bulk shear rate for a $2.8 \% \mathrm{CMC}$ solution is presented. Each slope is presented separately. To note is that the laminar flow data is co-linear as would be seen when a similar plot of tube viscometer data with five different diameter tubes were plotted on a pseudo shear diagram. With tube viscometry data the transition and subsequent turbulent data can be clearly observed. This is the same for the flume data as seen in Figure 1, but here for different slopes.

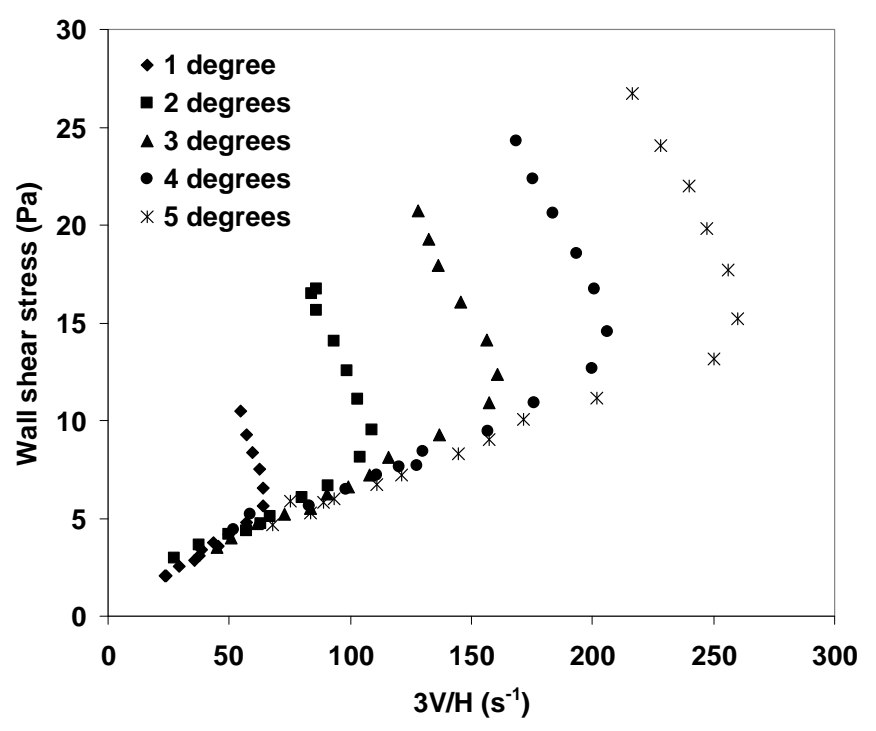

\section{Figure $2 \quad 2.8 \% \mathrm{CMC}$ in $300 \mathrm{~mm}$ rectangular flume}

In Figure 3, data for an $8 \%$ kaolin suspension flowing in a $300 \mathrm{~mm}$ rectangular flume is presented. The same general behaviour as for CMC can be observed. The co-linearity for the lowest slopes is not good. This is probably owing to the yield stress influence - at these low slopes the yield stress is preventing it from flowing uniformly.

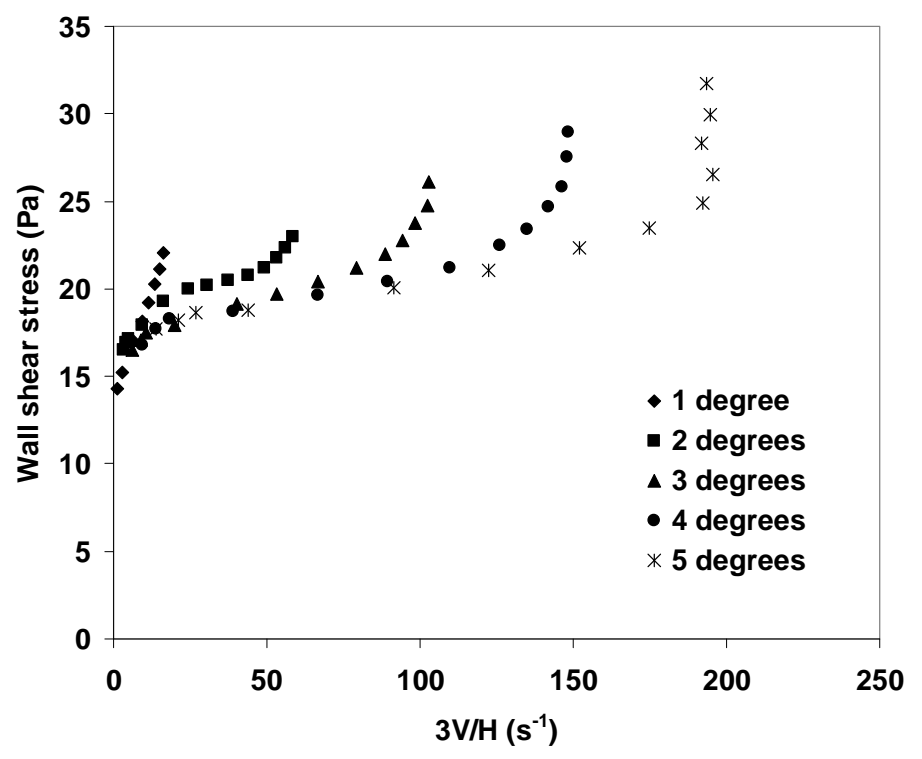

Figure $3 \quad 8 \%$ kaolin suspension in $300 \mathrm{~mm}$ rectangular flume 
The data presented in Figure 4 is for a $6 \%$ bentonite suspension flowing in a $300 \mathrm{~mm}$ wide rectangular flume. The $1^{\circ}$ slope data is missing as the yield stress was too high and prevented the fluid from flowing at all at that slope. Even for $2^{\circ}$ slopes the data shows that there was a problem for the fluid to flow. For the other slopes the same co-linearity and transition to turbulence can be observed as for the CMC and the kaolin.

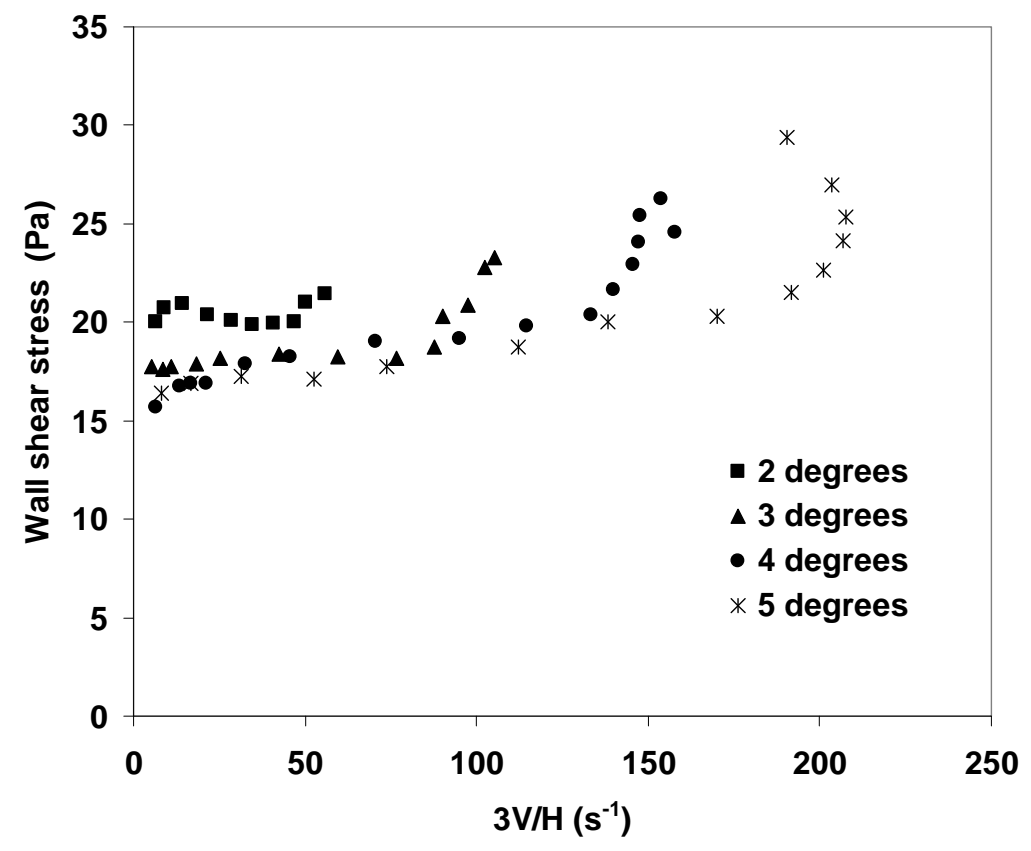

Figure $4 \quad 6 \%$ bentonite suspension in $300 \mathrm{~mm}$ rectangular flume

In Figure 5 the 1 and $5^{\circ}$ data from Figure 2 are shown. To be observed are the two circled points which indicate the laminar/transition points for slopes 1 and $5^{\circ}$.

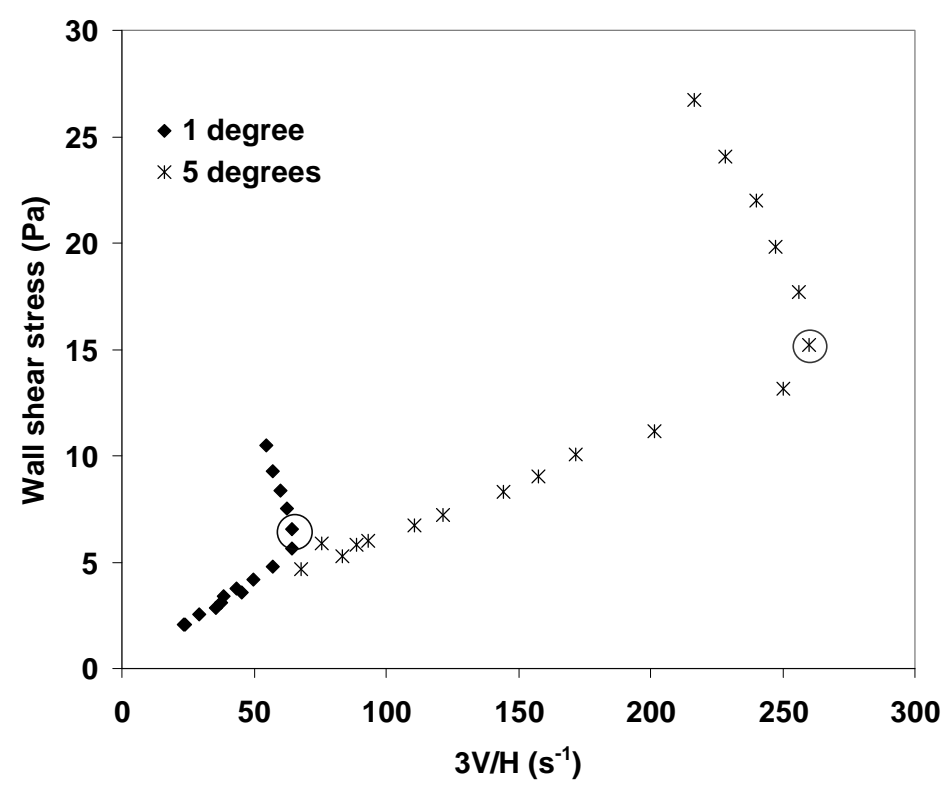

Figure $5 \quad 2.8 \% \mathrm{CMC}$ in $300 \mathrm{~mm}$ rectangular flume at 1 and $5^{\circ}$ showing transition 
Haldenwang et al. (2002) showed how different fluids and flume shapes could be presented on a Moody diagram when using the appropriate Reynolds number also presented in the same paper. The same data as presented in Figure 5 is presented in Figure 6 but here on a Moody diagram. The same two data points are again circled. On the Moody diagram it can be seen that they are the points where the data is starting to deviate from the laminar flow line presented by the $16 /$ Re relationship.

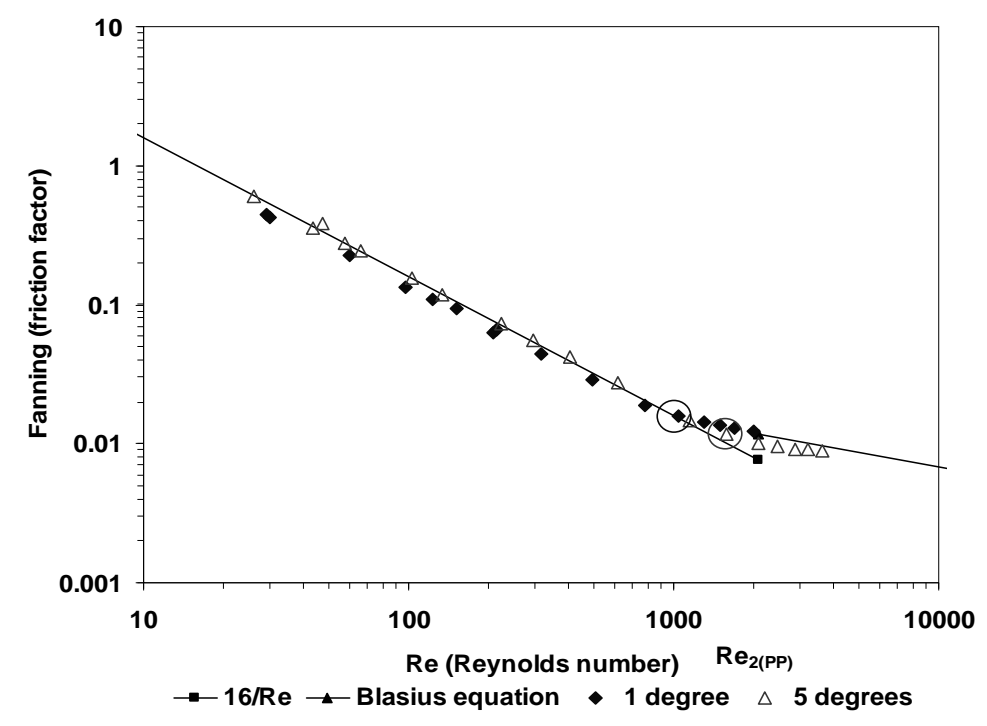

Figure 6 Moody diagram of $2.8 \%$ CMC showing transition

In Figure 7, the same two data sets are presented this time showing the relationship between Reynolds and Froude number. Haldenwang (2003) and Haldenwang et al. (2004b), used this to develop a model to predict the onset of transition. For a $5^{\circ}$ slope a power law relationship is shown which indicates the data in laminar flow. The circled point is where that data veers off from this relationship and indicates the onset of transition.

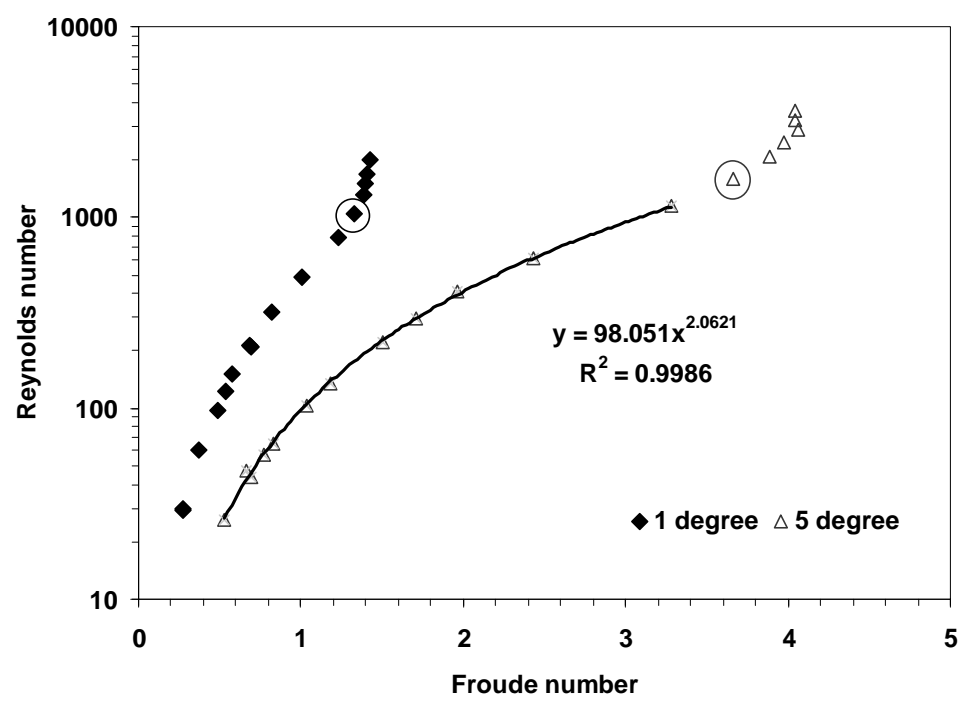

Figure $7 \quad 2.8 \%$ CMC in 300 rectangular flume (Froude number relationship showing transition) 


\section{Discussion}

The flow is assumed to be one-dimensional, with a flat free surface, with no ripples, and that surface tension effects are negligible.

The pseudo-shear sheet flow diagrams of the various materials show clearly that the data in the laminar region are collinear, which is highly reminiscent of the pseudo-shear pipe flow diagram. Furthermore, the turbulent branches are succinct, and different for each slope, which is also highly reminiscent of the pseudoshear pipe flow diagram. The collinearity in the laminar regime, where viscous forces dominate, is a clear indication that behaviour is independent of slope, and depends only on the rheology of the material.

The laminar region of the pseudo-shear sheet flow diagram is of fundamental importance for several reasons.

We have shown empirically that a plot of $3 \mathrm{~V} / \mathrm{H}$ versus $\tau_{0}$ will give a unique line for a given material for all values of $\mathrm{H}$. This means that in general the bulk shear rate $(3 \mathrm{~V} / \mathrm{H})$ is a unique function of the rheogram and the wall shear stress $\left(\tau_{0}\right)$, provided that there is no time dependency or slip at the wall and the flow is laminar.

Since $(3 \mathrm{~V} / \mathrm{H})$ is a unique function of the rheogram and the wall shear stress, it can be used for scale-up and design at any required slope and depth.

There is a fundamental relationship between the rheogram and the pseudo shear diagram, which now remains to be established, ie given a rheogram, we could use this fundamental relationship to construct a pseudo shear diagram $\left(3 \mathrm{~V} / \mathrm{H}\right.$ versus $\left.\tau_{0}\right)$, which could then be used for design in laminar flow. Conversely, we can reverse the process, as this fundamental relationship would provide the link or pathway between the pseudo shear diagram and the rheograms. Establishing this fundamental relationship provides the basis for the extension of this present investigation, and would be our logical next step.

The fact that the collinear data are in fact laminar is borne out by comparison with the Moody and Froude number plots, showing that the transition occurs at precisely the same point.

The pseudo-shear sheet flow diagrams also show that, when compared to the Moody and Froude number plots, the former indicate the point of transition much more clearly.

\section{Conclusions and recommendations}

The problem with this procedure is that one needs to conduct expensive flume tests which are viable for large projects but not for small designs.

There exists a need to relate the pseudo-shear sheet flow diagram to the rheological properties of the fluids, which provides the basis for further investigation.

\section{Acknowledgements}

The authors wish to acknowledge the National Research Foundation of South Africa as well as Cape Peninsula University of Technology for financially supporting this research.

\section{References}

Chow, Ven Te (1959) Open Channel Hydraulics. McGraw-Hill Book Co, Singapore.

De Kee, D., Chhabra, R.P., Powley, M.B. and Roy, S. (1990) Flow of viscoplastic fluids on an inclined plane: evaluation of yield stress, Chem. Eng. Comm. (96), pp. 229-239.

Haldenwang, R., Slatter, P.T., Chhabra, R.P. (2002) Laminar and Transitional flow in Open Channels for nonNewtonian Fluids. 15th International Conference on Hydrotransport. Banff, Canada. pp. 755-768.

Haldenwang, R. (2003) Flow of non-Newtonian flow in Open Channels. Unpublished D.Tech thesis. Cape Technikon. Cape Town, South Africa.

Haldenwang, R., Slatter, P.T. and Chhabra, R.P. (2004a) The Thin Film Approximation for Laminar Flow in Open Channels for non-Newtonian Fluids. International Seminar on Paste and Thickened Tailings, Cape Town, South Africa, March, 2004. 
Haldenwang, R., Slatter, P.T. and Chhabra, R.P. (2004b) Prediction of transition for non-Newtonian open channel flow. 12th International Conference on Transport and Sedimentation of Solid Particles, Prague, Czech Republic. pp. 387-396.

Haldenwang, R. and Slatter, P.T. (2006) Experimental procedure and database for non-Newtonian open channel flow. Journal of Hydraulic Research. Vol. 44 / Issue: 2, pp. 283-287. 